Prepared for the U.S. Department of Energy

under Contract DE-AC05-76RL01830

\title{
Inflow Characterization for Marine and Hydrokinetic Energy Devices. FY-2011: Annual Progress Report
}
MC Richmond
J Thomson
V Durgesh
B Polagye

June 2011

\section{Pacific Northwest}

NATIONAL LABORATORY

Proudly Operated by Battelle Since 1965 


\title{
DISCLAIMER
}

This report was prepared as an account of work sponsored by an agency of the United States Government. Neither the United States Government nor any agency thereof, nor Battelle Memorial Institute, nor any of their employees, makes any warranty, express or implied, or assumes any legal liability or responsibility for the accuracy, completeness, or usefulness of any information, apparatus, product, or process disclosed, or represents that its use would not infringe privately owned rights. Reference herein to any specific commercial product, process, or service by trade name, trademark, manufacturer, or otherwise does not necessarily constitute or imply its endorsement, recommendation, or favoring by the United States Government or any agency thereof, or Battelle Memorial Institute. The views and opinions of authors expressed herein do not necessarily state or reflect those of the United States Government or any agency thereof.

\author{
PACIFIC NORTHWEST NATIONAL LABORATORY \\ operated by \\ BATTELLE \\ for the \\ UNITED STATES DEPARTMENT OF ENERGY \\ under Contract DE-AC05-76RL01830
}

Printed in the United States of America
Available to DOE and DOE contractors from the Office of Scientific and Technical Information,
P.O. Box 62, Oak Ridge, TN 37831-0062;
ph: (865) 576-8401
fax: $(865)$ 576-5728
email: reports@adonis.osti.gov

\begin{abstract}
Available to the public from the National Technical Information Service, U.S. Department of Commerce, 5285 Port Royal Rd., Springfield, VA 22161 ph: (800) 553-6847 fax: $(703) 605-6900$ email: orders@ntis.fedworld.gov online ordering: http://www.ntis.gov/ordering.htm
\end{abstract}

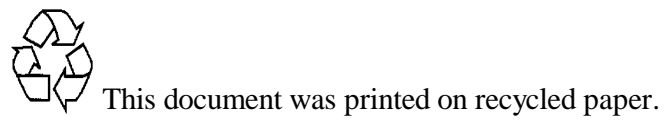




\title{
Inflow Characterization for Marine and Hydrokinetic Energy Devices. FY-2011: Annual Progress Report
}

\author{
MC Richmond \\ V Durgesh \\ J Thomson* \\ B Polagye*
}

June 2011

Prepared for

the U.S. Department of Energy

under Contract DE-AC05-76RL01830

Pacific Northwest National Laboratory

Richland, Washington 99352 


\section{Summary}

Marine and Hydro Kinetic devices (MHK) provide a way to harness energy from tides in costal regions. The Marrowstone Island site in Washington State is a potential location for installing MHK devices, since it experiences strong tides and associated currents. In order to quantify the effects of tidal currents on MHK devices, as well as the impact of MHK devices on the environment, a comprehensive study of tidal currents and flow is required. For this purpose, field studies were conducted at the Marrowstone Island site by the Pacific Northwest National Lab (PNNL) in collaboration with the Applied Physics Lab at the University of Washington (APLUW). These field studies entailed Acoustic Doppler Velocimetry (ADV), Acoustic Doppler Current Profiler (ADCP) and Conductivity, Temperature and Depth (CTD) measurements. The instruments used for this study were mounted on a tripod which was deployed at the site from the R/V Jack Robertson provided by the APL-UW. The ADV acquired single point temporally resolved velocity data from 17-21 Feb 2011, at a height of $4.6 \mathrm{~m}$ above the seabed. In contrast, the ADCP acquired the velocity profile of the entire water column from a height of 2.6 $\mathrm{m}$ above the seabed up to the sea-surface in 36 bins, with each bin of $0.5 \mathrm{~m}$ size. The ADCP acquired data from 11-27 Feb 2011 at a sampling frequency of $2 \mathrm{~Hz}$. CTD measurement data were acquired every 30 seconds at $1.85 \mathrm{~m}$ and $2.55 \mathrm{~m}$ above the seabed. Results from the ADV measurements showed that the flow is fully turbulent, with $-5 / 3$ slope in the inertial sub-range of the spectra. The ensemble average velocity profile obtained from ADCP measurements shows an agreement to both the log and power laws. 



\section{Contents}

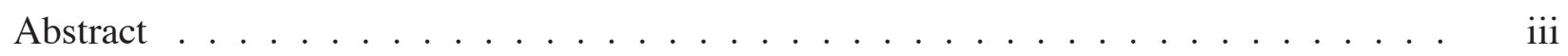

1.0 Introduction . . . . . . . . . . . . . . . . . . . . . 1.1

2.0 Study area and deployment . . . . . . . . . . . . . . . . . . . . 2.1

2.1 Acoustic Doppler Velocimetry (ADV) . . . . . . . . . . . . . . 2.1

2.2 Acoustic Doppler Current Profiler (ADCP) . . . . . . . . . . . . . 2.1

2.3 Conductivity, Temperature and Depth (CTD) $\ldots \ldots \ldots \ldots$

3.0 Initial Results . . . . . . . . . . . . . . . . . . . . . . . . . 3.1

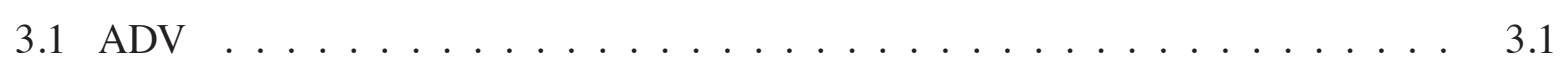

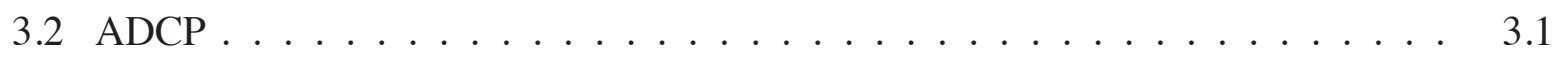

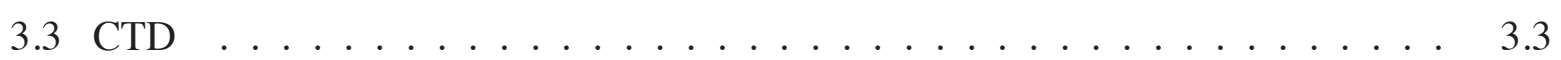

4.0 Data organization . . . . . . . . . . . . . . . . . . . 4.1

5.0 Future work . . . . . . . . . . . . . . . . . . . . . . 5.1

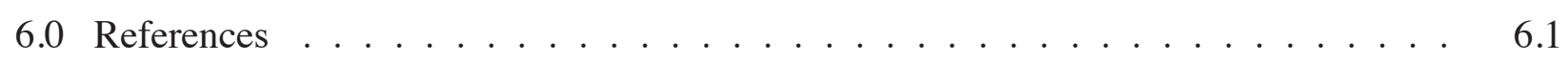




\section{Figures}

2.1 Marrowstone Island site location for ADV, ADCP and CTD measurement for this study. . . . . . . . . . . . . . . . . . .

2.2 (a) Tripod, instrument mounts, and ballast prior to deployment from the R/V Jack Robertson (University of Washington Applied Physics Labonatory), and (b) schematic of tripod with mounts and critical dimen-

sions. . . . . . . . . . . . . . . . . . .

2.3 Schematic showing a typical measurement sampling volume and location for ADCP and ADV. . . . . . . . . . . . . . . . . . .

3.1 ADV data: a) raw velocity data, and b) quality controlled velocity data. Colors indicate components of velocity ( $u$ and $v$ are the horizontal velocity components and $w$ is vertical velocity component). . . . . . . .

3.2 Average auto-spectral density function from ADV data: a) non-slack tides, and b) slack tides. Colors indicate components of velocity $(u$ and $v$ are the horizontal velocity components and $w$ is vertical velocity component). . . . . . . . . . . . . . . . . . . .

3.3 Velocities along the beam after quality control for ADCP measurements performed at Marrowstone Island site during Feb 2011 . . . . . . . . . . .

3.4 Magnitude of horizontal velocities along with flow directions for ADCP measurements performed at Marrowstone Island site. . . . . . . . . . . .

3.5 Histogram of the horizontal velocity direction at different heights from ADCP measurements: (a) $\$ \mathrm{~m}$ from seabed, (b) $10 \mathrm{~m}$ from seabed, and (c) $15 \mathrm{~m}$ from seabed.

3.6 ADCP measurements from 24-27 Feb 2011: (a) showing the horizontal velocity close to hub of a proposed MHK device where green shaded area represents horizontal velocity higher than $0.8 \mathrm{~m} / \mathrm{s}$ (i.e., non-slack tide), (b) ensemble averaged velocity profiles for non-slack tidal condition, (c) horizontal velocity direction histogram for the nonslack tidal condition, (d) ensemble averaged velocity profiles for slack tidal condition, and (e) horizontal velocity direction histogram for the slack tidal condition. . . . . . . . . . . . . . . . . . . . . . . .

3.7 Horizontal velocity as function of height above seabed for non-slack tidal condition, curve fitted with the power and log laws. The gray colored lines represent individual record of the horizontal velocity profiles, and red circle nharkers represent ensemble average of the horizontal velocity profiles. . . . . . . . . . . . . . . . . 
3.8 CTD (1.85 m above the seabed) measurements at Marrowstone Island site: (a) water depth, (b) salinity, and (c) temperature for entire deployment. . . . . . . . . . . . . . . . . . . . . . . . 3.7

5.1 Preliminary schematic of planned mooring setup for FY-2012. Courtesy Northwest National Marine Renewable Energy Center at the University of Washington. . . . . . . . . . . . . . . . . . . . . . 5.2 


\section{Tables}

$2.1 \quad$ List of all the measurements performed for FY-2011 study . . . . . . . . . . . . . . 2.1

4.1 Sampling design for all measurements performed for this study (FY-

2011). . . . . . . . . . . . . . . . . . . 4.1

$5.1 \quad$ Data collection expected to be performed for FY-2012 . . . . . . . . . . . . . 5.1 


\subsection{Introduction}

Marine and Hydro-Kinetic (MHK) devices are being developed and studied as a renewable source of energy. MHK devices extract energy from tidal currents using underwater turbines; their working principle is very similar to that of wind turbines. Although this technology is still in the nascent stages of development, in the past few years, MHK devices of various designs have been installed at different locations throughout the world. For optimal power generation from tidal currents using MHK devices, a detailed understanding of the fluid flow field surrounding these devices is essential, as turbulent fluctuations are known to negatively impact turbine performance and cause material fatigue and machine failure. This in turn decreases the lifespan of the MHK devices. Similar effects of turbulent fluctuations have been observed in wind turbines as well. Moreover, the quantification of fluid flow around MHK devices is also essential for assessing environmental effects of turbulent mixing on water quality and sediment transport at a given site.

The Marrowstone Island site in Washington State is a potential location for installing MHK devices as it experiences high tidal currents that are essential for energy production. Before installing MHK devices at this site, a detailed fluid flow field understanding was required in order to quantify the turbulence at the site, and its effects on MHK devices. For this purpose, the Pacific Northwest National Laboratory (PNNL), in collaboration with the Applied Physics Laboratory at the University of Washington (APL-UW), has carried out a detailed preliminary fluid flow field study using Acoustic Doppler Velocimetry (ADV) measurements, Acoustic Doppler Current Profiler (ADCP) measurements, and Conductivity, Temperature and Depth (CTD) measurements. For FY-2011, these measurements were performed continuously for two weeks, in order to collect data during both neap and spring tides, as well as during diurnal tidal variations. The FY-2011 measurements were a follow-on to data collected at the same site in FY-2010 (Richmond et al. (2011), Thomson et al. (2010)).

The ADV provided single point velocity measurements close to the lower extent of the rotor sweep of the MHK devices while the ADCP provided the velocity profile from the seabed up to the water surface. The CTD provided salinity, depth and temperature information at two different heights above the seabed for the site. These measurements collectively provided an insight into the site-specific tidal variations in the flow field as well as the conditions existing during different tidal cycles. These data can also be used to modify design tools developed for wind turbines, such as TurbSim (Kelley and Jonkman (2009)), for use in MHK turbine design. 


\subsection{Study area and deployment}

For the FY-2011 study, Acoustic Doppler Velocimetry (ADV), Acoustic Doppler Current Profiler (ADCP) and Conductivity,Temperature, and Depth (CTD) measurements were continuously performed at Nodule Point on the Marrowstone Island site $\left(48^{\circ} 01^{\prime} 55.440^{\prime \prime} \mathrm{N}, 122^{\circ} 39^{\prime} 41.340^{\prime \prime}\right.$ $\mathrm{W})$ for about two weeks. This site was selected for the study as it is being considered for future deployment of MHK devices. It was necessary to quantify the flow conditions at this site in order to determine the effects of turbulence on the MHK devices and the surrounding environment. For this purpose, all the measurements were performed for two weeks to obtain comprehensive tidal flow data. The site location and bathymetry data are shown in Figures 2.1 (a) and (b). Figure 2.2 shows the instrumentation tripod, which was deployed at a depth of $22 \mathrm{~m}$ at the Marrowstone Island site, using the R/V Jack Robertson provided by the University of Washington, Applied Physics Lab. A 1500 lbs ballast was added to the tripod for stability, as shown in the figure. The instrumentation tripod was designed and deployed in such a way that the ADV would be located $4.6 \mathrm{~m}$ above the seabed while the ADCP would be able to collect data from $2.1 \mathrm{~m}$ above the seabed up to the water surface. Details of all the measurement test conditions and locations are provided in table 2.1.

\begin{tabular}{|c|c|c|c|c|}
\hline Instrument & $\begin{array}{c}\text { Sampling } \\
\text { frequency }\end{array}$ & $\begin{array}{c}\text { Deployment } \\
\text { period }\end{array}$ & $\begin{array}{c}\text { Sampling } \\
\text { scheme }\end{array}$ & $\begin{array}{c}\text { Height above } \\
\text { seabed }\end{array}$ \\
\hline ADCP & $2 \mathrm{~Hz}$ & $11-27$ Feb 2011 & continuous & $2.1 \mathrm{~m}$ to sea surface \\
ADV & $32 \mathrm{~Hz}$ & $17-21$ Feb 2011 & continuous & $4.6 \mathrm{~m}$ \\
CTD -1 & $1 / 30 \mathrm{~Hz}$ & $11-22$ Feb 2011 & continuous & $1.85 \mathrm{~m}$ \\
CTD -2 & $1 / 30 \mathrm{~Hz}$ & $11-18$ Feb 2011 & continuous & $2.55 \mathrm{~m}$ \\
\hline
\end{tabular}

Table 2.1. $\quad$ List of all the measurements performed for FY-2011 study.

\subsection{Acoustic Doppler Velocimetry (ADV)}

ADV measurements have been extensively used to quantify turbulence and understand turbulent flows in rivers, oceans and flumes |Voulgaris and Trowbridge (1997), Garcia et al. (2005), Lane et al. (1998), Thomson et al. (2010), Richmond et al. (2011)]. For this study, a Nortek vector (6-MHz) ADV was used to collect high temporal resolution data at a single point. A typical schematic for the sampling volume of ADV measurements is shown in Figure 2.3. For this study, the ADV sampling volume is less than $0.01 \mathrm{~m}^{3}$. The ADV was setup to acquire data at a sampling frequency of $32 \mathrm{~Hz}$ and it acquired data for 4.5 days (i.e., from 17-21 Feb 2011). This sampling scheme was used to capture high-frequency fluctuations in velocity.

\subsection{Acoustic Doppler Current Profiler (ADCP)}

A RDI Workhorse Sentinel (600 kHz) ADCP was used to collect low temporal resolution velocity profile data from the seabed up to the surface. A typical schematic of sampling volume for ADCP measurement is shown in Figure 2.3. As seen in the figure, the ADCP sampling volume is significantly larger than the ADV sampling volume. The ADCP collected data at a sampling frequency of $2 \mathrm{~Hz}$, and it acquired data for 2.5 weeks continuously (i.e., 11-27 Feb 2011). 


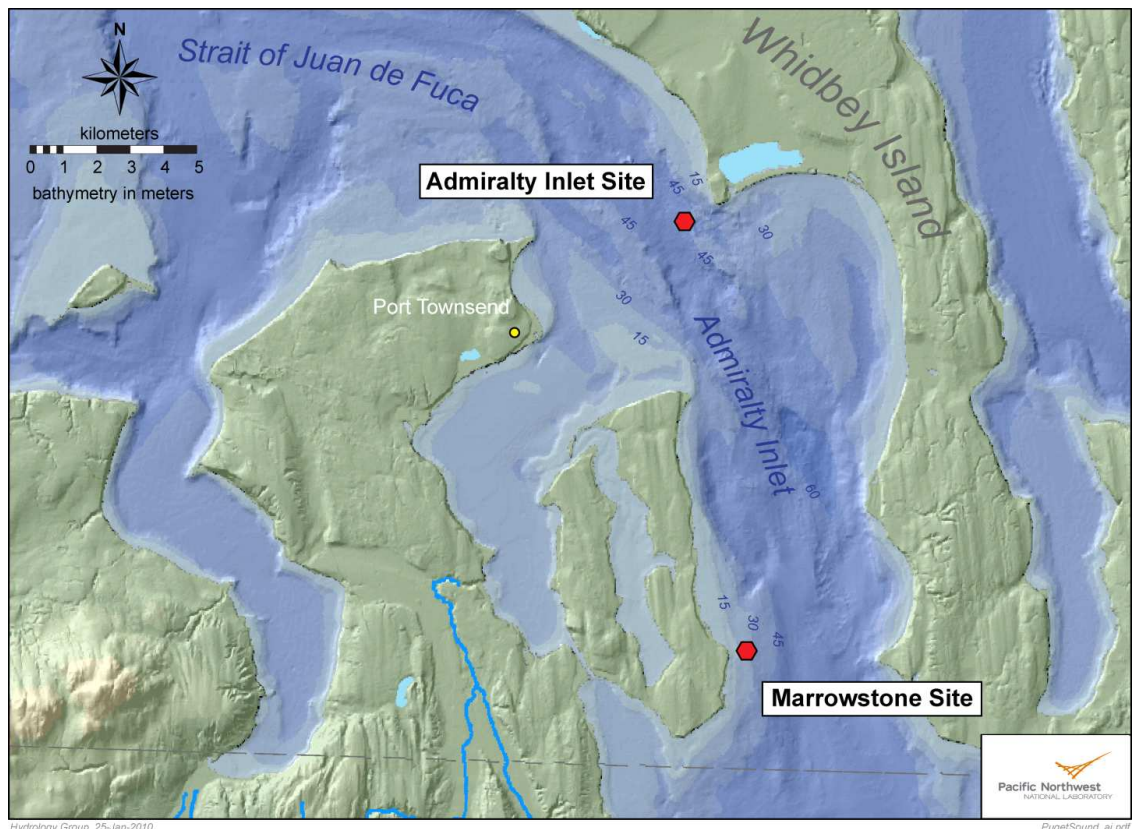

(a) Marrowstone and Admiralty sites

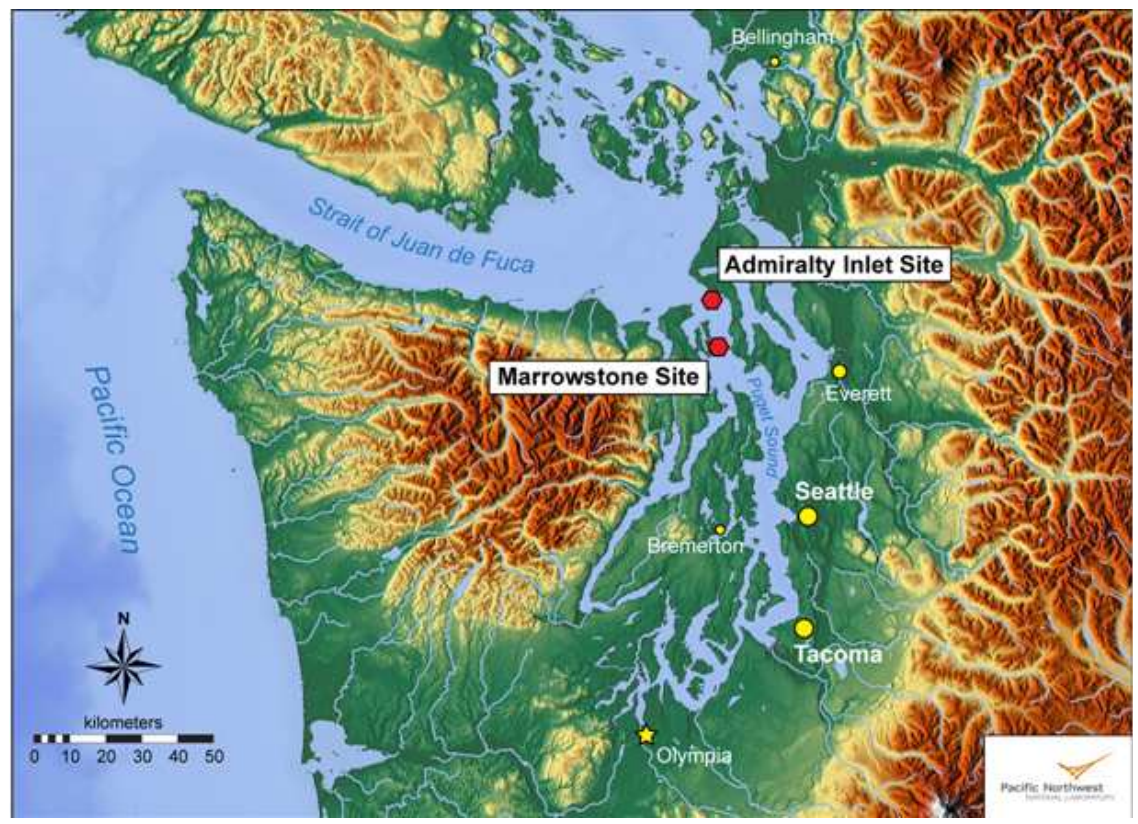

(b) Zoomed out view

Figure 2.1. Marrowstone Island site location for ADV, ADCP and CTD measurement for this study.

The data were recorded in beam co-ordinates in order to avoid the assumption of homogeneity required in the East-North-Up (ENU) coordinate system transformation. The ADCP recorded data from $2.6 \mathrm{~m}$ above the seabed up to the surface at a bin resolution of $0.5 \mathrm{~m}$, with a total of 36 bins. 


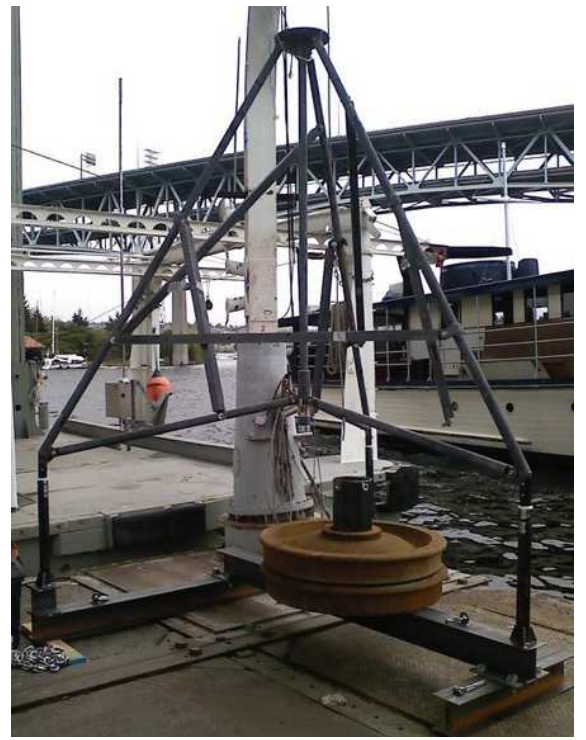

(a)

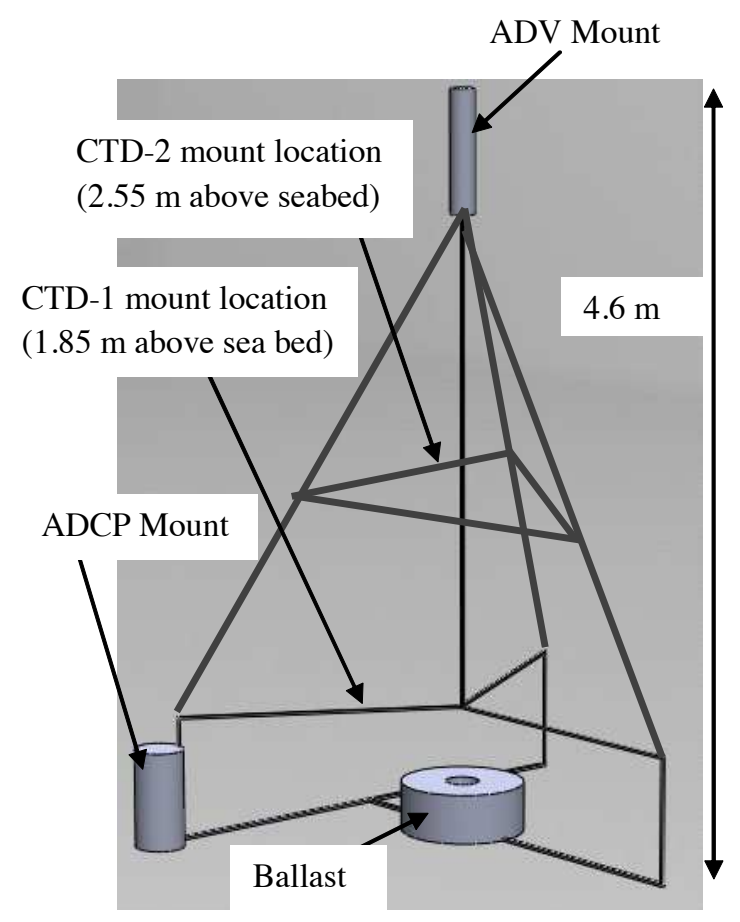

(b)

Figure 2.2. (a) Tripod, instrument mounts, and ballast prior to deployment from the R/V Jack Robertson (University of Washington Applied Physics Laboratory), and (b) schematic of tripod with mounts and critical dimensions.

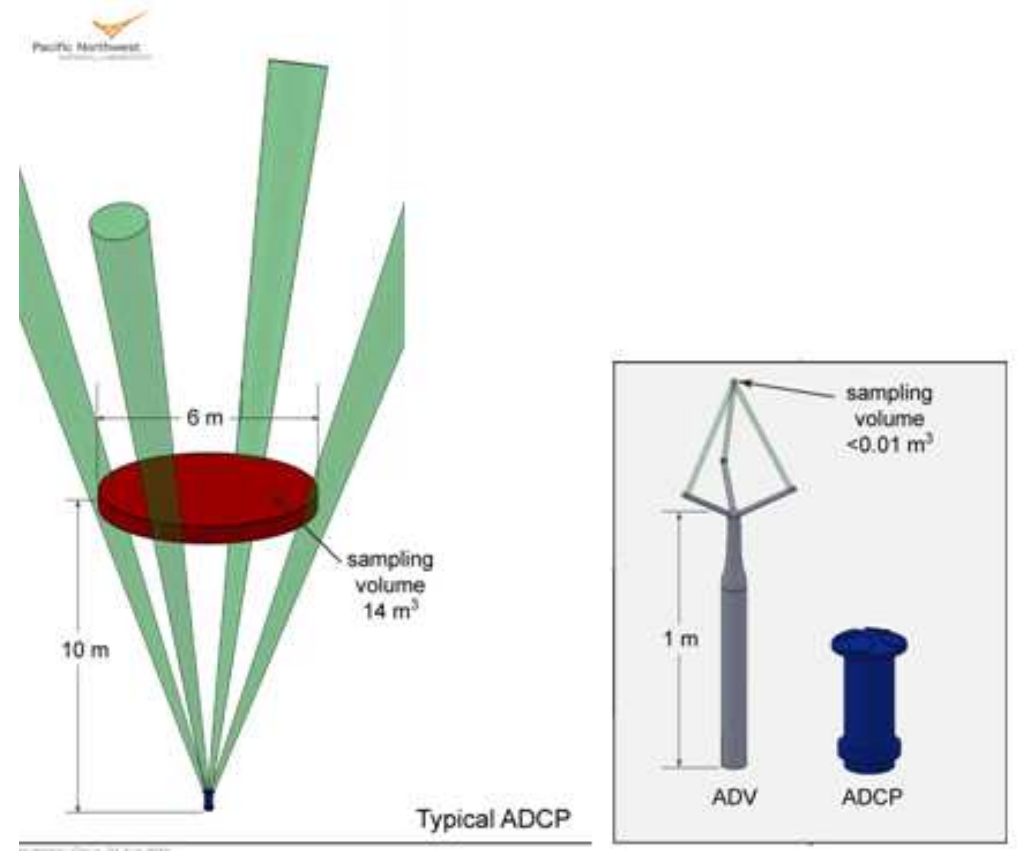

Figure 2.3. Schematic showing a typical measurement sampling volume and location for ADCP and ADV. 


\subsection{Conductivity, Temperature and Depth (CTD)}

In order to understand the flow conditions, Conductivity, Temperature, and Depth (CTD) data were collected using two Sea Bird Electronics SBE-37. The CTD instruments acquired data every 30s for approximately 1.5 weeks (i.e., 11-22 Feb 2011), and were attached to the tripod at a depth of $1.85 \mathrm{~m}$ and $2.55 \mathrm{~m}$ above the seabed. It should be noted that CTD at $2.55 \mathrm{~m}$ above the seabed stopped collecting data after 18 Feb 2011. 


\subsection{Initial Results}

\subsection{ADV}

The ADV measurements performed at the Marrowstone Island site provided single point high temporal resolution data. Before performing turbulence quantification from them, these ADV data were subjected to quality control procedures in order to remove noise and spurious data points. The quality control involved identifying the velocity data with low correlation and spikes [see Goring and Nikora (2002), Elgar and Raubenheimer (2001), Elgar et al. (2005), Thomson et al. (2010), Richmond et al. (2011) for detail] and then replacing these spurious data points with the running average. Raw ADV velocity data $(u, v$ and $w)$ and quality control velocity results are shown in Figure 3.1. After quality control, auto-spectral density functions are calculated from ADV data for slack and non-slack tidal conditions. The slack and non-slack tidal conditions are the periods when the horizontal velocity magnitude is less than $0.8 \mathrm{~m} / \mathrm{s}$ and greater than $0.8 \mathrm{~m} / \mathrm{s}$ respectively. For calculating horizontal velocity and auto-spectral density functions, the ADV data are divided into records of 2048 data points (i.e., data records with 64 seconds of data). This is done to ensure that data are quasi-stationary (i.e., statistical quantities not varying with time), which is essential for calculating auto-spectral density functions. Autospectral density functions for non-slack (i.e., horizontal velocity greater than $0.8 \mathrm{~m} / \mathrm{s}$ ) and slack (i.e., horizontal velocity less than $0.8 \mathrm{~m} / \mathrm{s}$ ) tidal conditions are shown in figures 3.2 (a) and (b) respectively. As observed from these figures, the spectra show a $-5 / 3$ slope in the inertial range, which is as expected for turbulent flows. The observed flattening of spectra at higher frequencies is due to the intrinsic noise present in the ADV. However, for the vertical velocity component, flattening of spectrum is not as prominent as the horizontal velocity components. This may due to biased distribution of noise levels between horizontal and vertical components which is a result of the coordinate transformation process used in ADV. Furthermore, the spectra have significant lower values for the non-slack condition as compared to slack condition, which is as expected for such flows.

\subsection{ADCP}

ADCP measurements were performed at the Marrowstone Island site for approximately 2.5 weeks. The ADCP acquired velocity profile data from a depth of $2.6 \mathrm{~m}$ above the seabed up to the surface, with a resolution of $0.5 \mathrm{~m}$, at a sampling frequency of $2 \mathrm{~Hz}$. These data were also quality controlled before further analysis. The quality control involved removing bins with low acoustic correlation, bins at or above the surface, and anomalous spikes. The bins close to air-water interface were removed because of the contamination of velocity data due to acoustic reflection from the water surface. After quality control of ADCP data, beam velocity data (from 11-23 Feb 2011)were plotted, as shown in Figure 3.3. The horizontal velocity magnitude (from 11-23 Feb 2011) is shown in Figure 3.4.

The horizontal velocity directions (for ADCP from 24-27 Feb 2011) at three different heights were extracted: (1) $4.6 \mathrm{~m}$ (i.e., at base of MHK devices), (2) $10.0 \mathrm{~m}$ (i.e., at hub of MHK devices), and (3) $15.0 \mathrm{~m}$ (i.e., at top of MHK devices). These velocity direction histograms are shown in figure 3.5. As observed from figure 3.5, there is a slight asymmetry in the flow direction as height from the seabed increases, which may be due to a bathymetric feature of the 

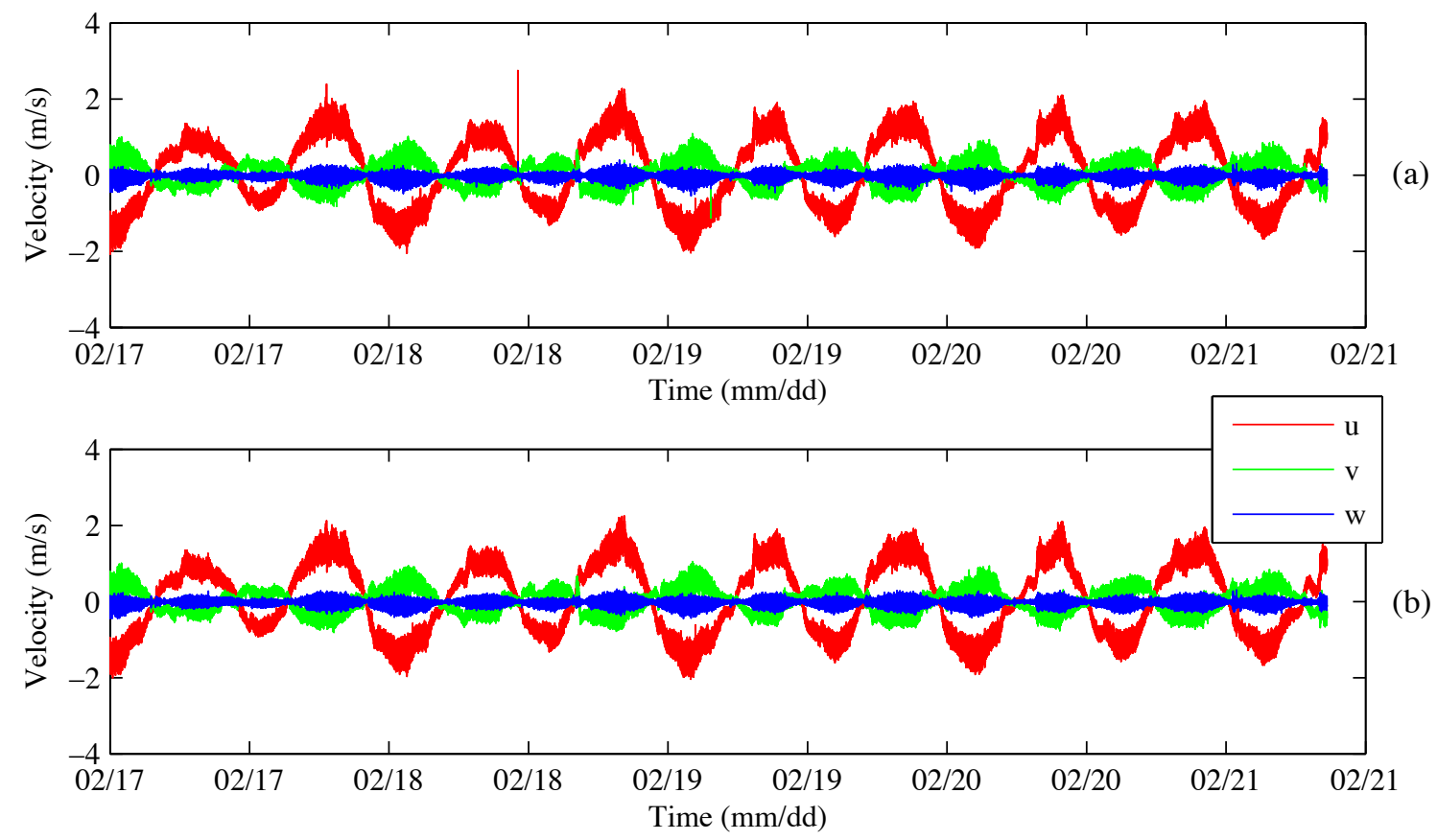

Figure 3.1. ADV data: a) raw velocity data, and b) quality controlled velocity data. Colors indicate components of velocity ( $u$ and $v$ are the horizontal velocity components and $w$ is vertical velocity component).
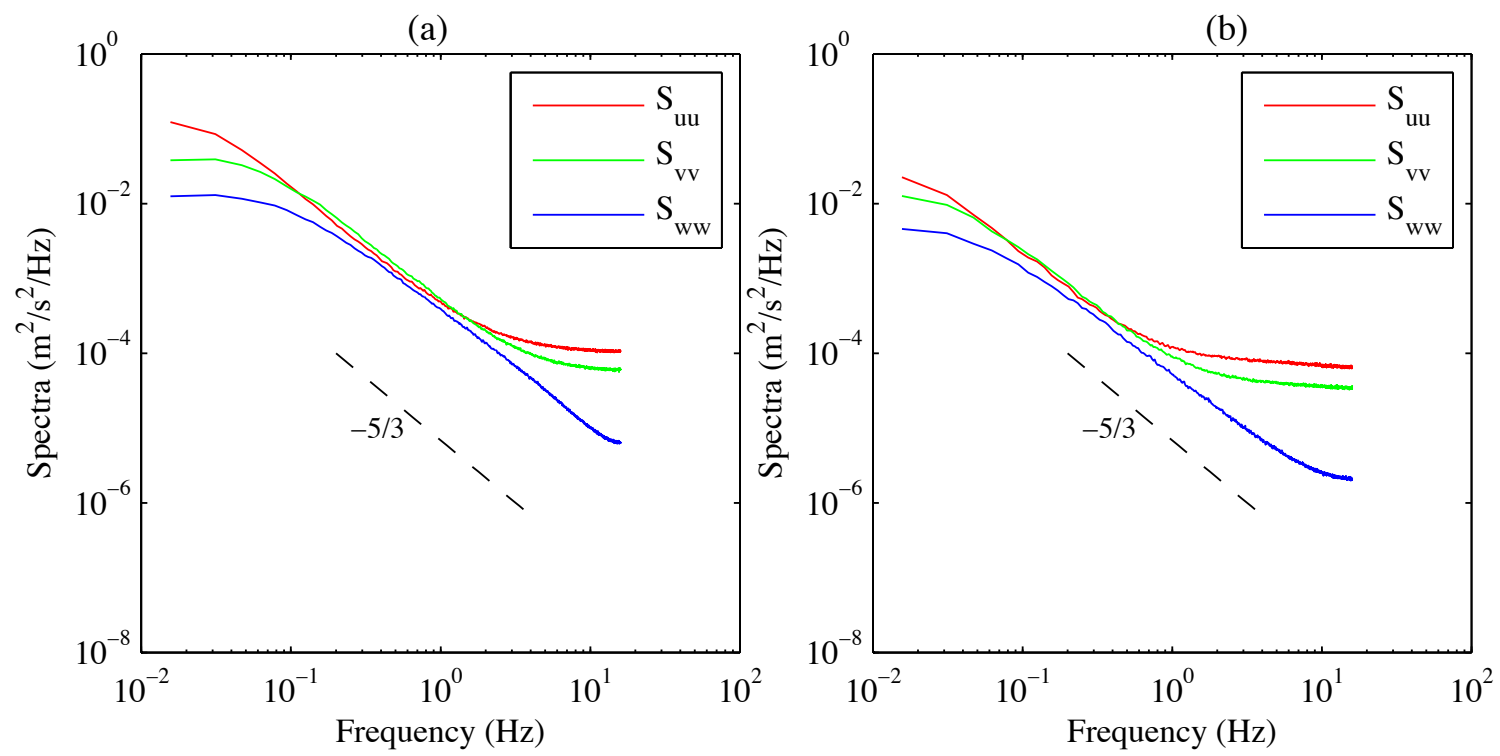

Figure 3.2. Average auto-spectral density function from ADV data: a) non-slack tides, and b) slack tides. Colors indicate components of velocity ( $u$ and $v$ are the horizontal velocity components and $w$ is vertical velocity component). 
Marrowstone Island site.

The horizontal velocity magnitude close to hub height of MHK devices was calculated and is shown in figure 3.6(a). The green shaded regions in the figure represent the horizontal velocity during the non-slack tidal condition (i.e., horizontal velocity greater than $0.8 \mathrm{~m} / \mathrm{s}$ ). Ensemble averaged velocity profiles for non-slack and slack tidal conditions were calculated, and are shown in figures 3.6(b) and (d) respectively. Figures 3.6(c) and (e) show the direction histograms of horizontal velocity for non-slack and slack tidal conditions respectively. As observed in these figures, the horizontal velocity has a dominant flow direction for the non-slack tidal condition, which is not observed for the slack tidal condition. It should be noted that a similar behavior is also observed for the ADCP data obtained from 24-27 Feb 2011 (not shown here).

Ensemble average of the horizontal velocity for the non-slack tidal condition is shown in figure 3.7. The ensemble averaged velocity data is curve fitted with the power and log laws (Peterson and Hennessey 1978, Stull 1993, Gooch et al.|2009, Kelley and Jonkman 2009), as shown in the figure. The power law is given as

$$
v(z)=v_{\text {hub }}\left(\frac{z}{z_{\text {hub }}}\right)^{\alpha},
$$

where $v_{h u b}$ is the reference velocity (i.e., horizontal velocity at the hub of MHK devices), $z$ is the height above the seabed, $z_{h u b}$ is the height of the hub from the seabed and $\alpha$ is the exponent for the power law. For a detailed description of power law, see article by Peterson and Hennessey (1978), Gooch et al. (2009), Kelley and Jonkman (2009). For the power law fit, horizontal velocity at $\sim 10 \mathrm{~m}$ above the seabed (i.e., $z_{h u b}$ ) is used as the reference velocity (i.e., $v_{h u b}$ ). The exponent for power law is estimated using a non-linear regression fit routine in Matlab, and the estimated exponent from the non-linear fit is $\sim 1 / 5.4$. The log law (Stull 1993. Kelley and Jonkman 2009) is given as

$$
v(z)=\frac{v_{\star}}{0.4} \ln \left(\frac{z}{z_{\circ}}\right)
$$

where $v_{\star}$ is the flow friction or shear velocity and $z_{\circ}$ is the surface roughness length. To fit the ensemble mean horizontal velocity data from the non-slack tidal condition, a nonlinear leastsquare regression fitting scheme was used and the estimated values obtained for $v_{\star}$, and $z_{\circ}$ are $0.088 \mathrm{~m} / \mathrm{s}$, and $0.043 \mathrm{~m}$ respectively. It is observed from the figure that ensemble average horizontal velocity profile is in better agreement with the log law as compared to the power law.

\subsection{CTD}

The data from CTD at $1.85 \mathrm{~m}$ above the seabed are shown in Figure 3.8. The temperature plot shows a decreasing trend in temperature while the salinity shows an increasing trend. The depth measurements shown in this figure also show a tidal variation. A similar trend was observed for the CTDs mounted at $2.25 \mathrm{~m}$ above the seabed. 

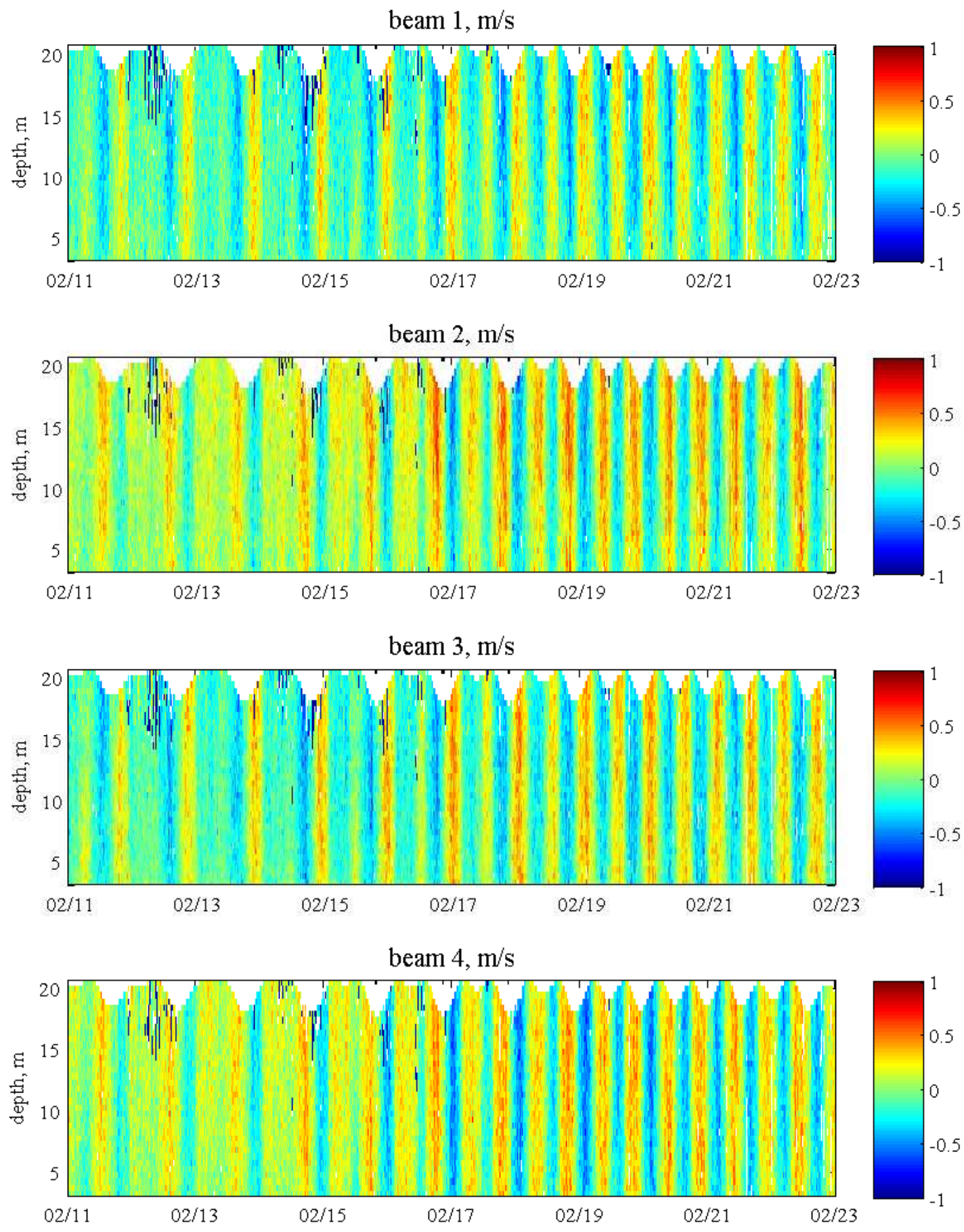

Figure 3.3. Velocities along the beam after quality control for ADCP measurements performed at Marrowstone Island site during Feb 2011. 


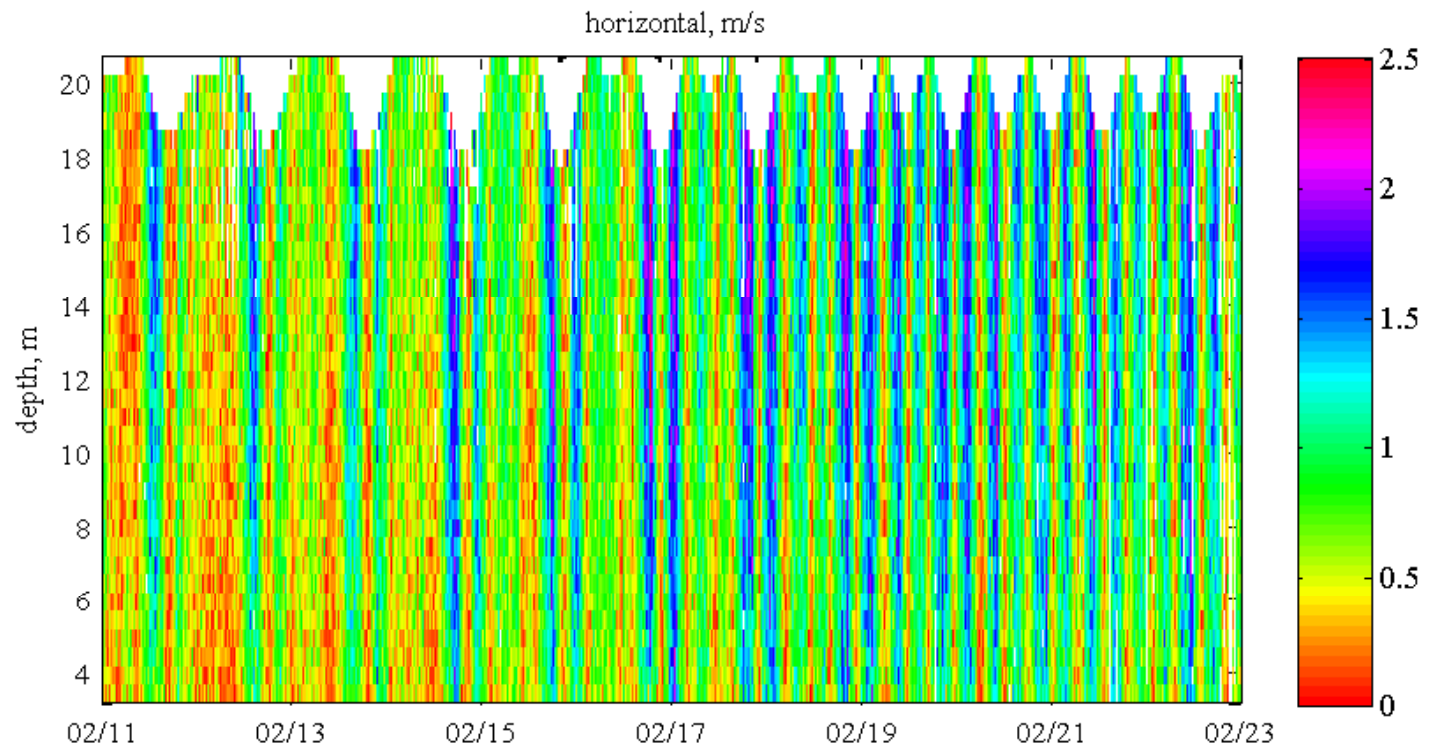

Figure 3.4. Magnitude of horizontal velocities along with flow directions for ADCP measurements performed at Marrowstone Island site.

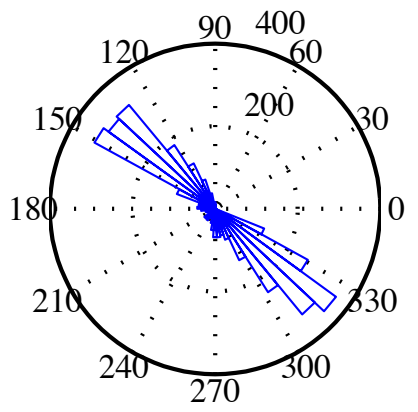

(a)

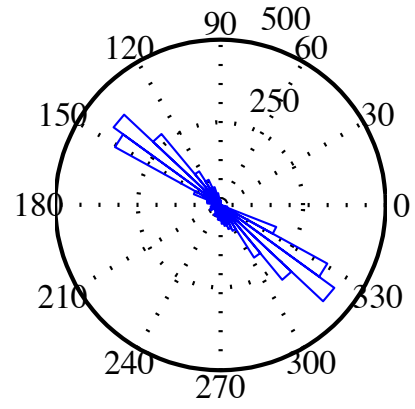

(b)

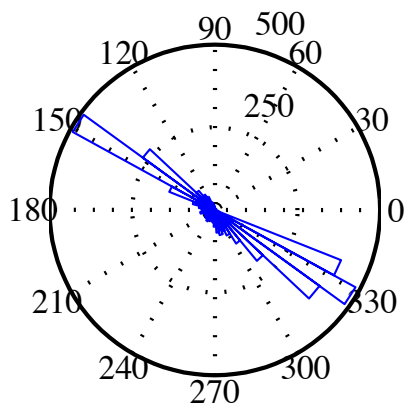

(c)

Figure 3.5. Histogram of the horizontal velocity direction at different heights from ADCP measurements: (a) $5 \mathrm{~m}$ from seabed, (b) $10 \mathrm{~m}$ from seabed, and (c) $15 \mathrm{~m}$ from seabed. 


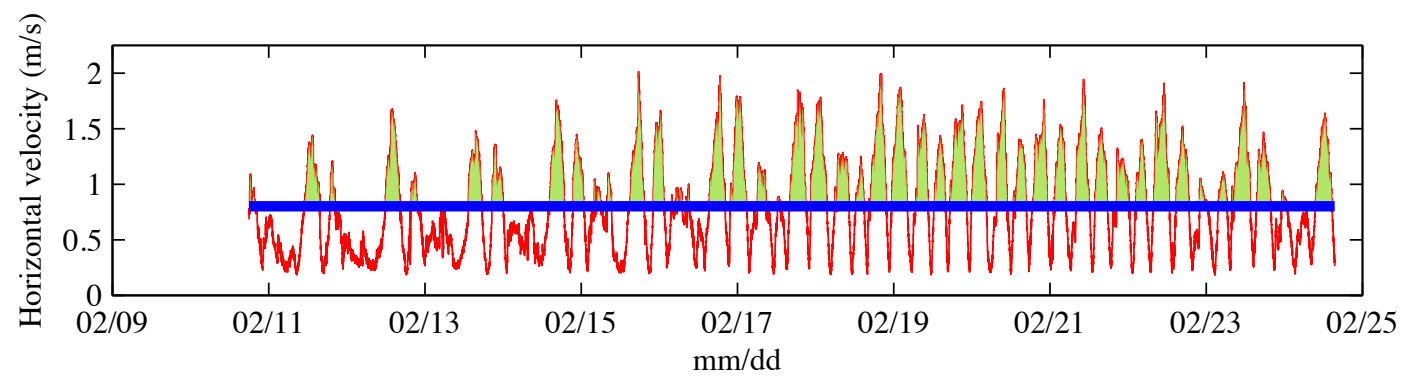

(a)

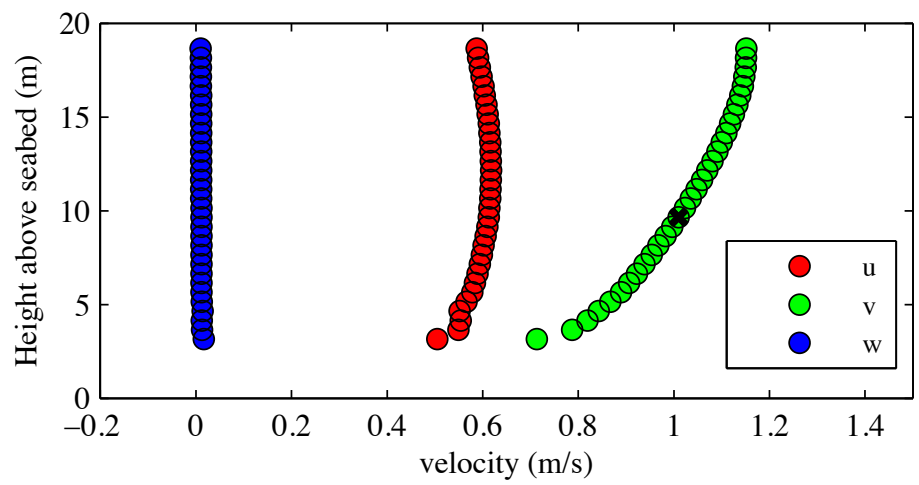

(b)

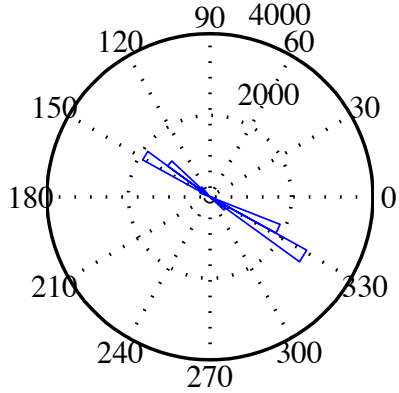

(c)

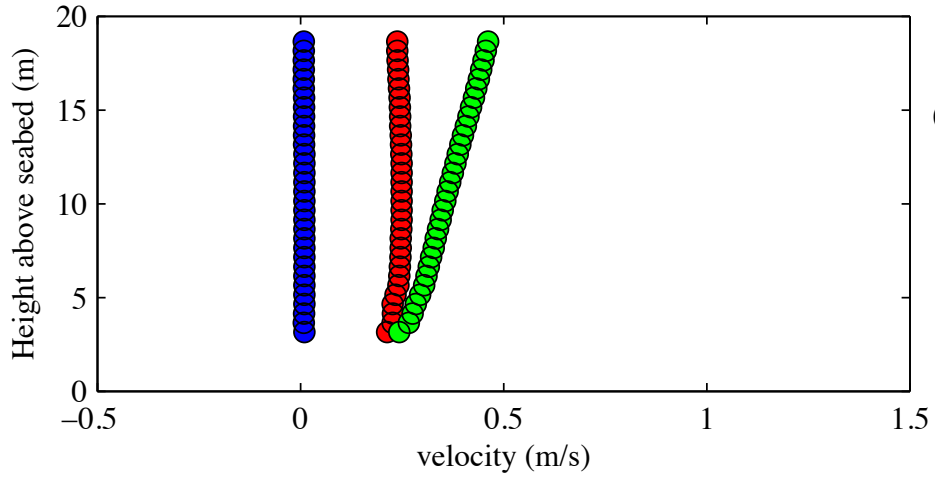

(d)

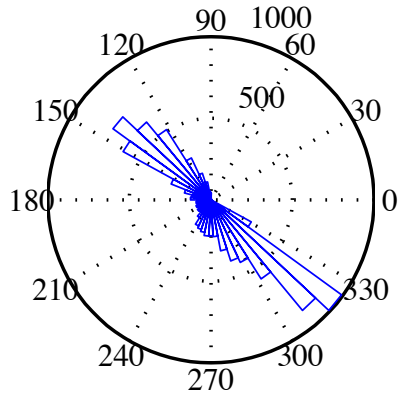

(e)

Figure 3.6. ADCP measurements from 24-27 Feb 2011: (a) showing the horizontal velocity close to hub of a proposed MHK device where green shaded area represents horizontal velocity higher than $0.8 \mathrm{~m} / \mathrm{s}$ (i.e., non-slack tide), (b) ensemble averaged velocity profiles for non-slack tidal condition, (c) horizontal velocity direction histogram for the non-slack tidal condition, (d) ensemble averaged velocity profiles for slack tidal condition, and (e) horizontal velocity direction histogram for the slack tidal condition. 


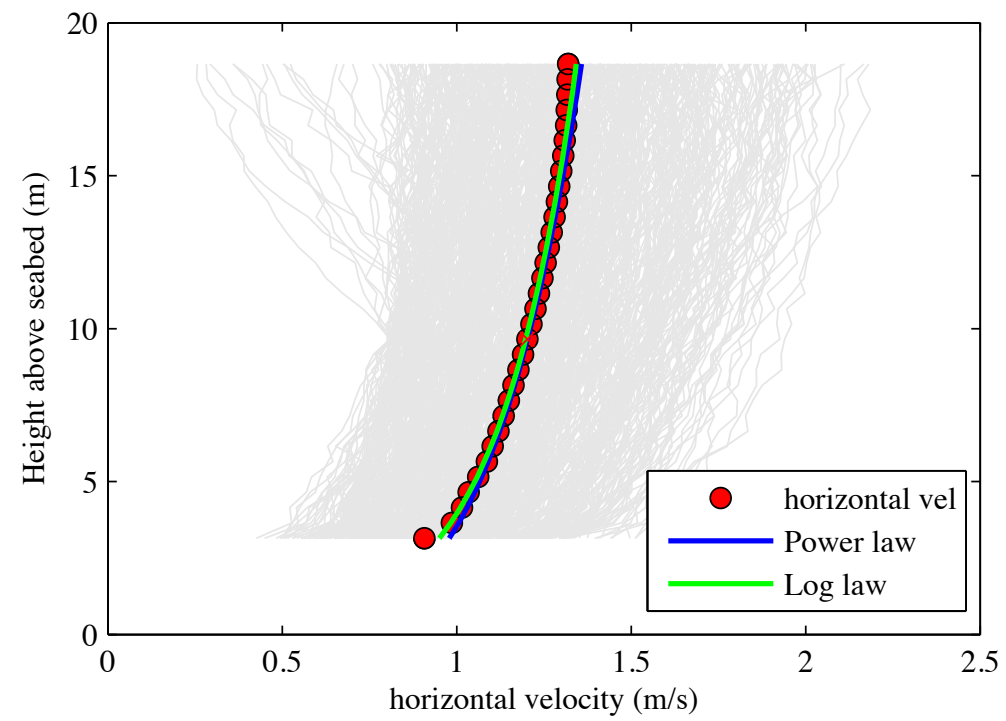

Figure 3.7. Horizontal velocity as function of height above seabed for non-slack tidal condition, curve fitted with the power and log laws. The gray colored lines represent individual record of the horizontal velocity profiles, and red circle markers represent ensemble average of the horizontal velocity profiles.
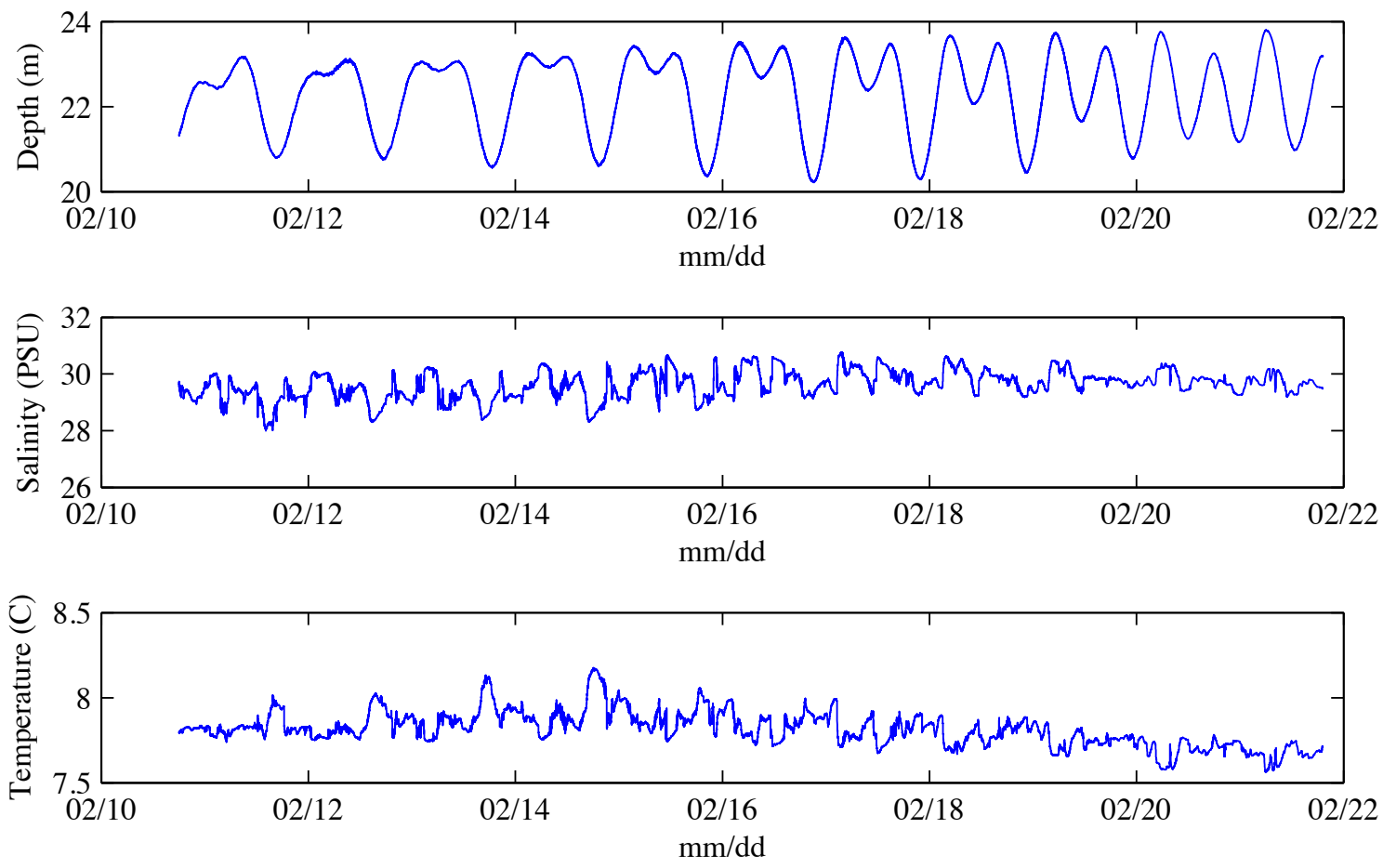

Figure 3.8. CTD (1.85 $\mathrm{m}$ above the seabed) measurements at Marrowstone Island site: (a) water depth, (b) salinity, and (c) temperature for entire deployment. 


\subsection{Data organization}

A list of all the measurements performed during FY-2011 at the Marrowstone Island site, along with deployment period, sampling scheme and data format is given in Table 4.1.

Table 4.1. Sampling design for all measurements performed for this study (FY-2011).

\begin{tabular}{|c|c|c|c|c|c|}
\hline Instrument & $\begin{array}{c}\text { Sampling } \\
\text { frequency }\end{array}$ & $\begin{array}{c}\text { Deployment } \\
\text { period }\end{array}$ & $\begin{array}{c}\text { Sampling } \\
\text { scheme }\end{array}$ & $\begin{array}{c}\text { Data } \\
\text { format }\end{array}$ & Comments \\
\hline ADCP & $2 \mathrm{~Hz}$ & $11-27$ Feb 2011 & continuous & Binary & Used two memory cards \\
ADV & $32 \mathrm{~Hz}$ & $17-21$ Feb 2011 & continuous & Binary & Low battery after 21 Feb \\
CTD -1 & $1 / 30 \mathrm{~Hz}$ & $11-22$ Feb 2011 & continuous & ASCII & \\
CTD -2 & $1 / 30 \mathrm{~Hz}$ & $11-18$ Feb 2011 & continuous & ASCII & Stopped working on 18 Feb \\
\hline
\end{tabular}

Data post-processing steps for ADCP measurements:

1. Convert binary data to ASCII format using in-house developed Matlab script.

2. Perform quality control on the ASCII data.

3. Convert the beam coordinate velocity data to ENU coordinate velocity data.

Data post-processing steps for ADV measurements:

1. Convert binary data to ASCII format using Nortek Vector software.

2. Perform quality control on the ASCII data.

3. Convert the instrument coordinate velocity data to ENU coordinate velocity data using information from sensors data file.

Post-processing steps were not required for the CTD data. 


\subsection{Data folder structure}

\subsubsection{ADCP}

For the ADCP measurements, the data were stored in two separate memory cards. The first memory card stored ADCP data from 11-23 Feb 2011 and the second memory card stored data from 24-27 Feb 2011. The data stored on the first and second memory cards are referred to as Set-1 and Set-2 respectively. The ADCP data acquired during FY-2011 were assembled and sorted in to folders as described below:

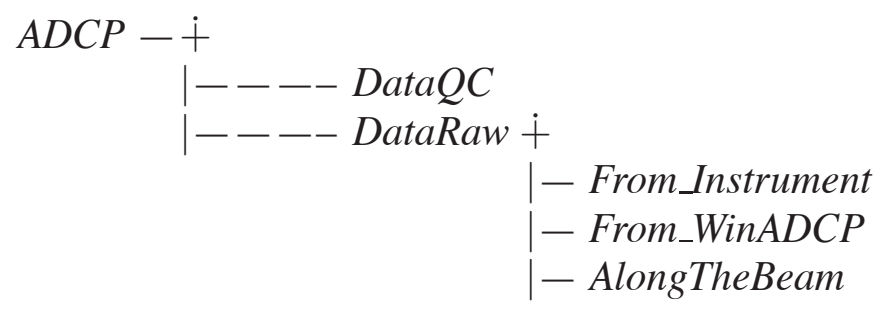

DataQC: Contains a Matlab binary format data file which has Quality Controlled (QC) time, depth, horizontal velocity data. These QC data are obtained from beam coordinate data, that are stored in folder DataBeamSystem.

DataRaw: Contains three folders From_Instrument, From_WinADCP, and AlongTheBeam, each containing ADCP data.

From_Instrument: Contains raw data from the ADCP instrument in binary format.

From_WinADCP: Contains a binary Matlab file format. This binary Matlab file is created from data stored in folder From_Instrument by using WinADCP export function. The binary Matlab file in this folder contains velocity data in East North Up (ENU) coordinate system.

AlongTheBeam: Contains a binary Matlab file. This binary Matlab file has velocities data in beam coordinate system which is obtained from data stored in the folder From_Instrument. The file was created using in-house Matlab script (other Matlab scripts available online can also be used for this purpose). 


\subsubsection{ADV}

The ADV data acquired during FY-2011 were assembled and sorted in folders as described below:

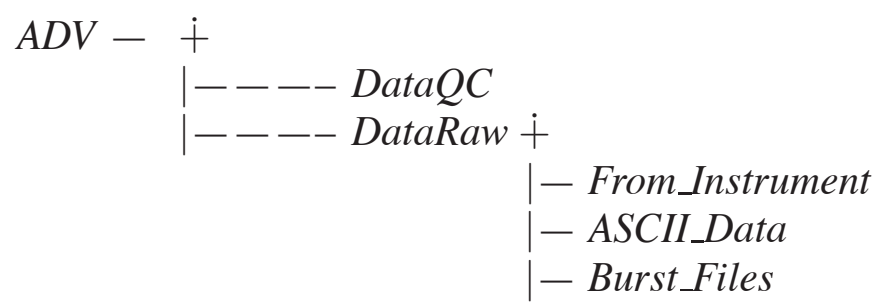

DataQC: Contains data in binary Matlab file format. The data stored in the folder ASCIIFormat are quality controlled and stored here in binary Matlab file format.

DataRaw: Contains three folders From_Instrument, ASCII_Data, and Burst_Files, each containing ADV data.

From_Instrument: Contains raw data from the ADV instrument in binary file format.

ASCII_Data: The raw data stored in the folder From_Instrument are converted to ASCII format using Nortek Vector software, and stored here.

Burst_Files: Contains the velocity data in ASCII format for individual bursts and these burst files are obtained from the data stored in the folder From Instrument using Nortek software. Here, it should be noted that for this deployment, ADV was set up to acquire data continuously. However, after four days of continuous data acquisition, the ADV battery was running low. So, after the fourth day, the ADV started acquiring data intermittently (i.e., acquiring data in bursts at irregular intervals). The first burst file has ADV data for first four days and the remaining burst files have velocity data at irregular intervals (see the ASCII files in this folder for further clarification).

\subsection{CTD}

The data acquired from CTD measurements during FY-2011 at Marrowstone Island site were stored in the folder CTD. Since data were in ASCII format, no further processing was necessary. 


\subsection{Future work}

For FY-2012, studies similar to those carried out in FY-2011 are planned to be conducted at the Admiralty site (location shown in figure 2.1). As opposed to the tripod setup used in FY-2011 studies, a mooring setup will be used be in FY-2012 studies, a preliminary schematic is shown in figure 5.1. The mooring schematic shown in the figure is still in the planning phase and final design and setup will be ready before the FY-2012 deployment. Moreover, the new designed mooring setup will have the ability to position the ADVs and CTDs at different heights above the seabed, which will allow for simultaneous acquisition of velocity and CTD data at several locations. Like the tripod setup, the mooring setup will also have the ADCP close to the seabed, which will enable the ADCP to obtain the complete velocity profile of the water column above it. A tentative experimental schedule/plan for FY-2012 is given in Table 5.1.

Table 5.1. Data collection expected to be performed for FY-2012.

\begin{tabular}{|c|c|c|c|c|}
\hline Measurement & Instrument & $\begin{array}{c}\text { Sample } \\
\text { duration }(*)\end{array}$ & $\begin{array}{l}\text { Sampling } \\
\text { frequency }\end{array}$ & $\begin{array}{l}\text { Mounting } \\
\text { position }\end{array}$ \\
\hline Curre & $\mathrm{ADCP}$ & 3-4 weeks & $2 \mathrm{~Hz}$ & Bottom \\
\hline Curre & ADV & 3-6 days & $32 \mathrm{~Hz}$ & height or mult \\
\hline Temperature profile & CTD & 3-6 days & $1 \mathrm{~Hz}$ & Multi-point through wate \\
\hline Salinity profile & CTD & 3-6 days & $1 \mathrm{~Hz}$ & Multi-point through water column \\
\hline
\end{tabular}

(*) Sampling duration can vary depending on the project requirement, the available budget and instrument type. 


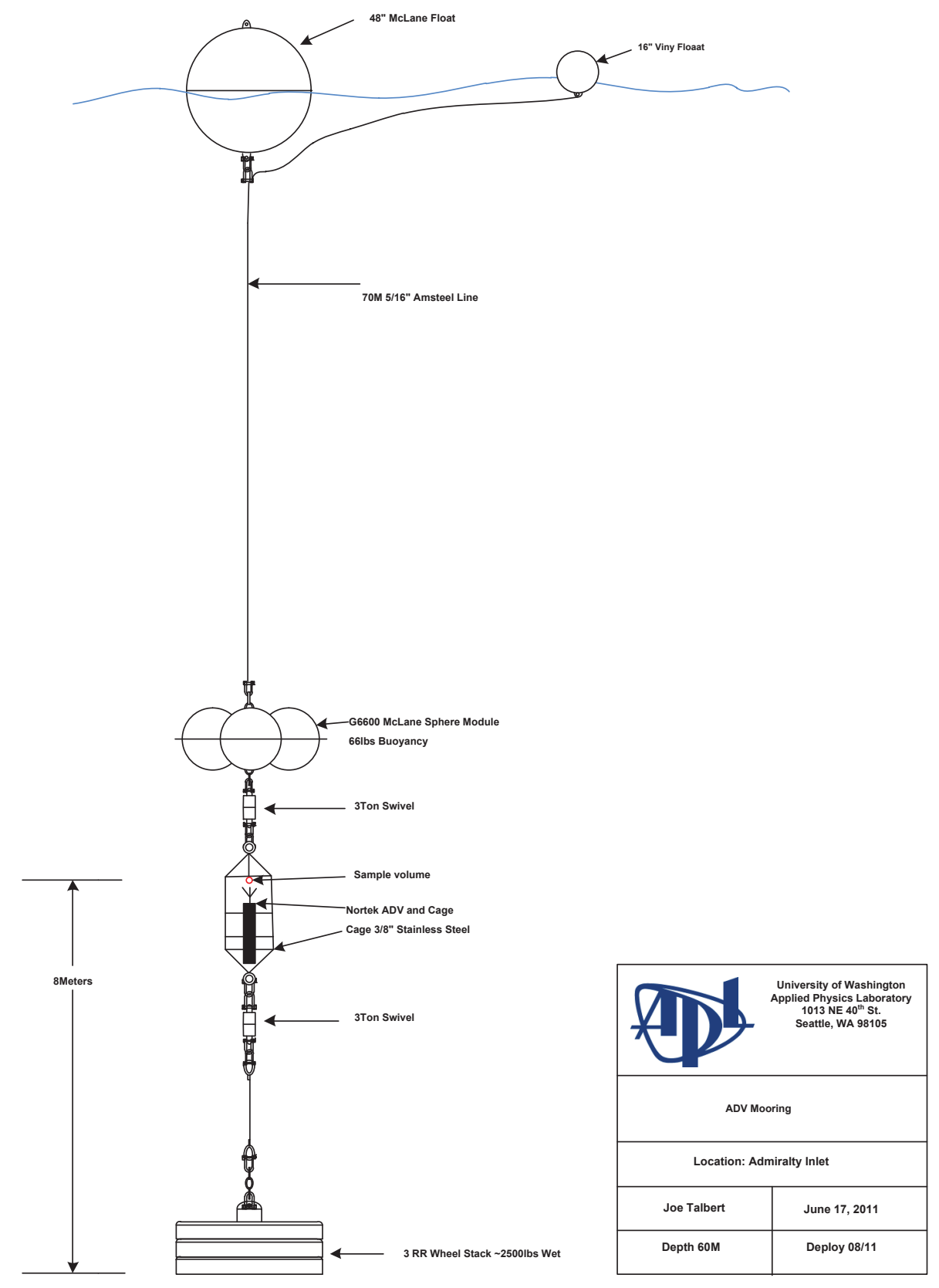

Figure 5.1. Preliminary schematic of planned mooring setup for FY-2012. Courtesy Northwest National Marine Renewable Energy Center at the University of Washington. 


\subsection{References}

Elgar S and B Raubenheimer. 2001. "Current meter performance in the surf zone.” Journal of Atmospheric and Oceanic Technology 18:1735-1745.

Elgar S, B Raubenheimer, and RT Guza. 2005. "Quality control of acoustic doppler velocimetry data in the surfzone." Measurement Science Technology 16:1889-1893.

Garcia CM, MI Cantero, Y Nino, and MH Garcia. 2005. "Turbulence measurements with acoustic doppler velocimeters.” Journal of Hydraulic Engineering 131(12):1062-1073.

Gooch S, J Thomson, B Polagye, and D Meggitt. 2009. "Site characterization for tidal power." In OCEANS 2009, MTS/IEEE Biloxi - Marine Technology for Our Future: Global and Local Challenges, pp. $1-10$.

Goring DG and VI Nikora. 2002. "Despiking acoustic doppler velocimeter data." Journal of Hydraulic Engineering 128(1):117-126.

Kelley N and BJ Jonkman. 2009. Turbsim User's Guide: Version 1.50. Research Report TP-500-46198, National Wind Technology Center, National Renewable Energy Laboratory.

Lane SN, PM Biron, KF Bradbrook, JB Butler, JH Chandler, MD Crowell, and SJ Mclelland. 1998. "Three-dimensional measurement of river channel flow processes using acoustic doppler velocimetry." Earth Surface Processes and Landforms 23:1247-1267.

Peterson E and J Hennessey. 1978. "On the Use of Power Laws for Estimates of Wind Power Potential.” Journal of Applied Meteorology 17(3):390-394.

Richmond M, V Durgesh, J Thomson, and B Polagye. 2011. Inflow Characterization for Marine and Hydrokinetic Energy Devices. FY-2010 Annual Progress Report. Annual Progress Report PNNL-19859, Pacific Northwest National Laboratory.

Stull RB. 1993. An Introduction to Boundary Layer Metrology. Kluwer academic publishers.

Thomson J, B Polagye, M Richmond, and V Durgesh. 2010. "Quantifying turbulence for tidal power applications." Oceans 2010, MTS/IEEE.

Voulgaris G and JH Trowbridge. 1997. "Evaluation of Acoustic Doppler Velocimeter (ADV) for turbulence measurements." Journal of Atmospheric and Oceanic Technology 15:272-289. 